\title{
O Signo da Invenção na Poesia Concreta e noutras poéticas experimentais
}

\author{
Rogério Barbosa da Silva
}

Resumo

\begin{abstract}
Este trabalho pretende mostrar que os experimentalismos brasileiros e português constituíram uma poética da invenção fundamental, ao estabelecer um diálogo com as artes visuais e performáticas e com a tecnologia. Essas poéticas constituíram, simultaneamente, um modo de reler as tradições literárias ocidentais, a retomada da longínqua tradição da poesia visual e uma reflexão crítica sobre a linguagem, o fazer artístico e o contexto social de que ela emerge.
\end{abstract}

Palavras-chave: Poesia Concreta. Poesia Experimental. Representação.

Trecho de entrevista:

- Mas por que falar em poesia concretista?

Diga-se "concretismo", apenas, e estará ressalvada a poesia.

Mário Quintana. Caderno H

Concretismo: dez em matemática. Dez em política. Zero em português. / Poesia marginal: zero em português. Dez em biologia. Zero em matemática.

Chacal. In: Dez conversas

A exemplo do que fez Augusto de Campos, no texto "O 'Rock'n Roll' da Poesia Concreta", ou "The gentle art of making enemies" (Campos, 1989, p. 181-184), este artigo começa pela provocação bem humorada à Poesia Concreta. Assim, Mário Quintana faz irônica oposição entre movimento poético e poesia propriamente dita, lançando farpas sobre a produção do grupo paulista. Chacal opõe duas linhas da recente poesia brasileira, cujos conflitos e concepções acerca do que seja poesia se explicitam, imediata e respectivamente, nas vertentes concreta e marginal da poesia brasileira, opondo a matemática da composição no verso concreto à vida e à compreensão dos sujeitos fraturados, aspectos centrais da poesia marginal. Em ambos os casos, entretanto, os textos se produzem sob o rótulo da entrevista: inventada, no caso de Quintana, e real, no de Chacal. Neste sentido, torna-se evidente a manifestação de um incômodo de ambos os poetas quanto à clássica pergunta: "O que acha de...?". Reagem, assim, a nosso gosto pelo rótulo e pelo apaziguamento do incômodo. 
Dessa armadilha poetológica (isto é, a convenção fossilizada, a apreensão apriorística pelas regras), a poesia sempre tende a escapar, por ser de sua natureza não se acomodar às vozes públicas ou aos rótulos da crítica. Num de seus "atos poéticos", o poeta português Alberto Pimenta pôs isso em evidência ao queimar, na Feira do Livro de Lisboa, o seu livro de ensaios mais famoso, O silêncio dos poetas, durante a comemoração do Dia de Camões (10 de junho).

Em seu Ato Poético, de acordo com um registro feito em $O$ Jornal, de 14 de junho de 1991, Pimenta, com a cabeça envolta numa larga faixa de pano branco, desafiando a seriedade daquele espaço dedicado à cultura, escreve com tinta e pincel num cartaz a mensagem: "basta um olhar em redor para notar que ninguém percebeu que chama cultura à cabeça atada". Depois, sobe a um banco, tira do bolso um exemplar do livro, antes de declarar:

Tantos anos de que eu precisei para entender por que é que as aflitivas cabeças desse ramo da ordem chamado cultura aprovaram este meu livro: porque embora ele vá contra a cabeça atada, sempre é um acto da cabeça. Aprovando este e reprovando o resto, insinuam que eu podia ser um homem da cultura como eles; não perceberam que eu gosto mais de ser só um homem. Todos pretenderam sempre fazer da arte um modo de cultura, quer dizer, fazer duma liberdade do indivíduo uma virtude da sociedade. Até os próprios artistas, não só os filhos da puta confessos, desde Platão até Freud. Simbolicamente, isto é, pelo nome, estão todos aqui dentro. Que deus lhes abra o reino dos céus: não faz mais que cumprir o que prometeu'. E dito isto pega fogo ao livro que tem na mão [...] Atraído pelo ajuntamento, há um polícia que vem espreitar, mas sem conseqüências. Com ar compenetrado, o poeta aguarda em silêncio que o fogo destrua por completo a sua obra. E quando, longos minutos depois, as chamas se extinguem no improvisado altar, Pimenta olha em volta e lança a última provocação da noite: 'Agora que isto acabou, podeis ir ler outro. Ite, poesia est. O vosso destino é comer e cagar'. E foi-se embora. (PIMENTA, 1992, p. 40)

Sendo um dos poetas fundamentais na poesia portuguesa contemporânea, Alberto Pimenta passou a integrar o movimento da Poesia Experimental Portuguesa a partir dos anos 70. Em seu campo de interesses estético e crítico, a reflexão sobre a poesia do experimentalismo sempre se manifesta, pois se trata de uma poesia que busca desautomatizar a linguagem e se instaura sob o signo da negação, do silêncio, da invenção. O poeta português explicita, com freqüência em seus trabalhos, a emancipação da poesia e da linguagem em relação aos preceitos retóricos, de gêneros ou mesmo de um objeto pré-determinado pelas convenções acadêmicas ou de mercado. O "ato poético" na Feira de Livros de Lisboa evidencia essa preocupação de questionar a apreensão do artístico segundo os esquemas mentais programados pela acomodação crítica em prol da liberação dos múltiplos sentidos da percepção e da crítica.

As poéticas experimentais, entre as quais está incluída a poesia concreta, são poéticas que se preocupam com a formulação de novas linguagens, vislumbrando as relações da poesia com outras artes ou com outras linguagens não-verbais. Trata-se de uma poesia que aprofunda uma investigação da linguagem, caracterizando-a, especialmente, por seu estatuto de signo. Desse modo, mais do que revelar os fundamentos culturais de uma dada língua nacional, tais poetas têm interesse especial na descoberta dos parentescos ou das diferenças entre as línguas, muitas vezes expresso em poemas bilíngües. Portanto, o conceito "experimental" não tem, neste trabalho, a carga pejorativa assinalada por Adorno, nem sequer, por sua evocação permanente do novo, implica o modismo novidadeiro. Significa, antes, uma atitude diante da linguagem, dentro também de um ethos de negação do status quo e de uma visão crítica da realidade presente e passada. 
Nesse sentido, verificamos que a recusa das premissas do concretismo e de outras poéticas experimentais, também de vanguarda, resulta principalmente do questionamento que os seus poemas impõem à escrita. O desejo de uma poesia "verbivocovisual", de uma "arte objetal", na expressão de Haroldo de Campos, trouxe uma intensa reflexão sobre a escrita tradicional, o que implicou, por sua vez, questionar a representação inerente à linguagem. Baseados em teóricos como Luís Costa Lima, o próprio Alberto Pimenta e o filósofo Didi-Huberman, entre outros, observamos que a arte pode desvelar o caráter duplo dos signos, pois apresenta 0 paradoxo de ser e, ao mesmo tempo, representar. A explicitação desse paradoxo serve, portanto, para denunciar o fato de que, muitas vezes, a escrita camufla a ilusão que cerca o referente. Este é um campo que Poesia Concreta e outras formas do experimentalismo procuraram explicitar, conforme nos mostra, por exemplo, esta afirmativa de Décio Pignatari: "... com a revolução industrial, a palavra começou a deslocar-se do objeto a que se referia, alienou-se, tornou-se objeto qualitativamente diferente, quis ser a palavra /flor/ sem a flor; e desintegrou-se ela mesma..." (PIGNATARI, 1975, p. 42).

Por sua vez, Alberto Pimenta salienta que a apreensão artística também tem de ser "libertada" do "logos" racional, na medida em que é preciso indagar sobre o modo de representar assumido por uma determinada arte, sobre as intenções subjacentes do artista, e não a partir da mera apreensão das mensagens ou do "discurso" ali realizado. A "análise feita a partir de um interesse de conhecimento nivelador do método de apreensão de toda a espécie de "mensagem" ou "discurso" só serve aos interesses daqueles a quem a arte serve mas não interessa como arte" (PIMENTA, 2003 , p. 11). Portanto, podemos observar, por um lado, a tendência dessas poéticas em "arruinar o alicerce formal e simbólico que reveste a palavra", o que se faz pela utilização de signos híbridos, enfatizando uma dimensão visual (olhar e ler), por exemplo, pela construção de uma poética do ilegível, tal como acontece na poesia de Ana Hatherly. Por outro lado, os deslocamentos produzidos por essas poéticas forçam o leitor/usuário à mudança de comportamento, pois os "textos" diante de seus olhos exigem a participação de todos os seus sentidos. Ao esvaziar a escrita tradicional, ao negar os referentes seguros, essas novas escrituras levam os "leitores" a se defrontarem com a perda, com a ruína e com a morte, como nos mostra DidiHuberman em seus estudos sobre arte.

Uma outra dimensão importante na consideração dessas poéticas é o fato de que, considerado o ciclo vital dos experimentalismos e o das vanguardas, torna-se necessário refletir sobre a permanência de uma poética radical na obra individual dos poetas que compuseram os principais grupos de vanguarda nos anos 50 e 60, bem como sobre a multiplicação de tendências no experimentalismo a partir das revoluções tecnológicas pós anos 80 . Neste sentido, compreendemos tais poéticas como instantes/etapas de uma "poética de invenção".

Percebemos que o conceito de "invenção"-visto aqui como ligado à imaginação, à descoberta e à permanente atualização dos meios técnicos e lingüísticos-permite uma maior dinâmica para a análise dessas formas poéticas. Esse conceito possibilitanos pensar os deslocamentos temporais, processados na crítica de vários autores estudados, quando procuram re-inscrever poéticas inventivas do passado, a exemplo do barroco e de uma longa tradição da visualidade no ocidente ou da visualidade ideogramática do Oriente. Além disso, apesar do decantado fim da utopia a partir dos anos 90, com o conseqüente declínio do conceito de vanguarda, a dimensão reflexiva e crítica dessas poéticas de invenção (ou ideográficas, com diria Alberto Pimenta) 
permaneceu viva na obra criativa e crítica da maioria dos autores que fizeram a poesia de vanguarda da segunda metade do século XX. Transformadas, suas obras não perderam o fôlego criativo, contaminando inúmeros poetas de gerações mais novas e posicionando-se com vigor diante dos problemas da realidade contemporânea.

Neste contexto, podemos afirmar que, com o uso da tecnologia, ou se quisermos com o uso das técnicas disponíveis, as poéticas experimentais renovam a linguagem de tal forma que nos tentam fazer ouvir de novo o silêncio inaugural, como neste poema-canção de Arnaldo Antunes, cujo título é exatamente "O silêncio":

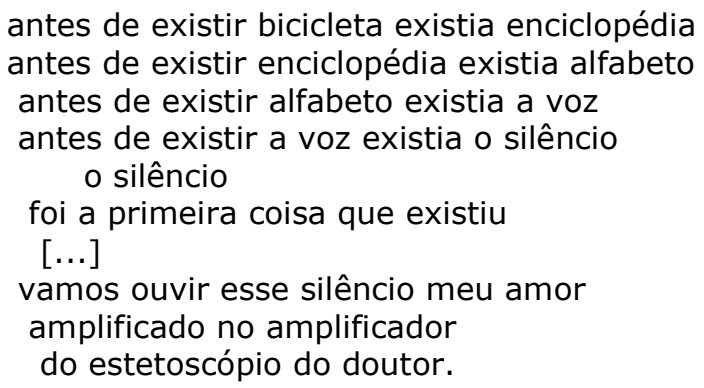

(ANTUNES, 1996)

Nesse poema-canção, percebemos o processo de desnaturalização promovido pelo homem a partir da fabricação de seus utensílios. Assim, paradoxalmente, o homem contemporâneo estaria condenado a ouvir o silêncio jamais ouvido a partir de seus próprios utensílios técnicos. Neste sentido, é interessante referir aqui à tese de Antônio Risério de que a "poesia é uma prática paleolítica". A partir da paleontologia, ele articula a relação entre a linguagem e a motricidade técnica: "É dominante entre os palentólogos a tese de que existe possibilidade real de linguagem a partir do momento em que a pré-história exibe utensílios, já que existe uma conexão neurológica entre uma coisa e outra." (RISÉRIO, 1998, p. 45)

Assim, o uso da tecnologia pela poesia não será apenas uma questão de fetiche, embora ela adquira às vezes essa feição em alguns trabalhos poéticos. Se, por um lado, ela é um suporte diferente e mais dinâmico para determinadas esferas da criação artística, por outro ela é também uma ferramenta de investigação fenomenológica, uma extensão do olho e das mãos dos poetas, em particular dos que se aventuram nas zonas intermediárias das poéticas digitais, videográficas e outras. A Poesia Concreta abriu as fronteiras da página, trouxe para ela a possibilidade do tridimensional, que já se insinuava na idéia de uma poesia "verbivocovisual". O vídeo tornou essa poesia possível. Em Nome (1993), de Arnaldo Antunes, podemos verificar como um poema pode ser ao mesmo tempo um objeto plástico, um poema objeto, e um exercício de mediação crítica da linguagem. No poema "Dentro", a palavra-imagem transcende ao caligrama e a animação faz a palavra dobrar-se sobre si mesma, fundindo o sonoro, a voz, e a imagem. Esse poema estilhaça a referência, pondo em crise a linguagem da representação.

Também o poeta português Melo e Castro, ao desenvolver sua "Poética do Pixel", produz uma poética que opera com a tridimensionalmente na tela do computador. Faz do pixel a unidade mínima da percepção visual, que opera simultaneamente com o verbal e o não-verbal. É o elemento "branco de significado", mas que pode diferencialmente adquirir todos os significados, de acordo com sua posição. Ao se caracterizar como uma poética, a infopoesia impõe um uso e uma produção da tecnologia que não podem ser vistos como meros produtos na sociedade de consumo. 
Isso permite a humanização da tecnologia, isto é, um uso refletido para o humano, definindo um "espaço plural em que contido e continente se equivalem, entremudando-se", diz o poeta, citando Deleuze: "'Dobrar-desdobrar já não significa simplesmente tender-distender, contrair-dilatar, mas envolver-desenvolver, involuirevoluir' e por isso o andar de baixo da dobra onde fica a matéria se prolonga no andar de cima da dobra onde se desenvolve a alma." (CASTRO, 1998, p. 16).

Entre as novas possibilidades de expressão poética, podem ainda ser mencionadas a holopoesia e a poesia sonora. A primeira, conforme os conceitos-chave apresentados pelo poeta Eduardo Kac, pode ser definida pela instabilidade espacial, pela imaterialidade (pois é um espaço constituído por "photons", portanto não tangenciável e não concreto), pela quarta dimensão, pela interatividade, pelo movimento, pela percepção e por conceitos relativos a esse campo. Novamente, tal como enunciamos anteriormente a propósito da poesia de Arnaldo Antunes e da vídeopoesia em geral, há uma retomada e uma transformação das proposições e práticas instituídas pela Poesia Concreta, tais como a exploraração do pluridimensional, a idéia de fazer o leitor participar e experimentar o poema como um objeto, entre outras. A transformação está nas novas possibilidades do suporte, que possibilitam ao leitor, visto como usuário, uma interatividade materializada. Eduardo Kac indica como possibilidades criadas por esses meios a manipulação da relação temporal (a espacialização do tempo) e das informações acumuladas, que podem ser controladas de forma a gerar novas experiências de percepção. Todavia, será preciso ressaltar a diferença existente entre uma produção holográfica genuína e outras que já tenham sido produzidas em outras mídias. Kac enfatiza que pode não haver nenhuma diferença significativa, por exemplo, entre um castelo de cartas e um holograma deste mesmo objeto, porém a poesia holográfica produz algo muito além da mera ilusão da tridimensionalidade (KAC, [2004]). A razão dessa afirmação pode ser encontrada no fato de que esse tipo de poética potencializa uma série de questões que já vem sendo discutida desde a década de 50, com a Poesia Concreta: a descontinuidade sintática e espacial, a fluidez e a imaterialidade do signo, o espaço vazio, a interposição semântica e a reversibilidade do tempo, entre as mais importantes, talvez.

Uma outra dimensão dessa arte de invenção é o olhar crítico sobre a própria produção, o que não só ajuda a manter a coerência de um projeto, mas, principalmente, revela uma consciência permanentemente atenta quanto aos aspectos criativos da obra de arte. No fim dos anos 90, entretanto, percebemos que vários desses autores organizaram coletâneas de poemas que retomam trabalhos do período áureo das neovanguardas, ou editaram livros inéditos, que, entretanto, dialogam com produções anteriores. Augusto de Campos, por exemplo, reeditou Viva Vaia (2001), revisando aspectos gráficos, acrescentando textos e um cd com leituras de seus poemas clássicos. Logo a seguir, publicou Não (2003), livro que reafirma também alguns procedimentos que caracterizaram sua obra e que, entretanto, aponta outros rumos de sua produção. O mesmo pode ser dito em relação à poesia de Ana Hatherly, com seu Um calculador de improbabilidades (2001) e com os inéditos O pavão negro (2002) e Itinerários (2002). Alberto Pimenta, Affonso Ávila e Sebastião Nunes também publicaram inéditos, que nos possibilitam dialogar com produções anteriores. E. M. de Melo e Castro e Haroldo de Campos, respectivamente, organizaram coletâneas de seus poemas em Antologia Efémera (2000) e Crisantempo (1998). Por fim, Décio Pignatari re-organiza seu Poesia pois é poesia (2004). Todas essas publicações marcam simbolicamente um período de 50 anos, o que nos leva a refletir sobre o caráter, simultaneamente, meditativo e de memória dessas produções. 
Nesse re-posicionamento do experimentalismo, o tempo torna-se um elemento bastante significativo, pois desvela não só as dobras temporais como princípio criativo, mas também um modo de análise e validação do rigor, da pertinência e da abertura que perpassam a obra desses mesmos poetas. Quanto ao aspecto da abertura em suas obras, verificamos, por exemplo, a importância do diálogo que elas estabeleceram com as novas tecnologias ao longo do tempo, abrindo também perspectivas para as gerações mais novas afeitas a tecnologias de ponta e herdeiras das mesmas tradições inventivas. O novo experimentalismo, conforme tais poéticas de invenção, não se limita a repetir os gestos inaugurais do passado. Significa, principalmente, uma reflexão tensa a partir da linguagem e dos meios disponíveis.

A leitura e a análise das propostas da Poesia Concreta revelaram-nos o seu papel fundamental no estímulo a outras práticas do experimentalismo no Brasil depois dos anos 50, não só revalorizando o modernismo como ainda contribuindo intensamente para a atualização da crítica brasileira. Porém, é no diálogo entre as várias tendências do experimentalismo, como se verifica na aproximação entre as correntes brasileiras e o experimentalismo português, que se manifesta o imenso valor das discussões suscitadas pelo projeto artístico e pelos programas-manifestos dessas vanguardas poéticas. Nesses feixes cruzados de múltiplas propostas da criação poética é que percebemos, efetivamente, que o fazer da Poesia Concreto e suas "provocações" constituem uma forma de meditação sobre a linguagem e sobre o estar no mundo. Como diria Haroldo de Campos, as novas realidades se impõem ao indivíduo e o obrigam a testar novos modos de existir e de conhecer o universo.

Abstract

This work intends to show how experimental poetries in Brazil and Portugal constituted a fundamental poetry of invention, when establishing a dialogue with the visual art, performance art and with the technology. Those poetries constituted, simultaneously, a way of reading again the western literary traditions, renewing the lost tradition of the visual poetry, and a critical reflection about the language, the artistic conscience and the social context of which it comes.

Key words: Concrete Poetry. Experimental Poetry.Representation.

Referências

ANTUNES, Arnaldo. O Silêncio. In: . O silêncio. São Paulo: Ariola, [1996]. Digital, stéreo.

CAMPOS, Augusto. Teoria da poesia concreta - textos críticos e manifestos 1950-1960. 2. ed. São Paulo: Livraria Duas Cidades, 1975.

CASTRO, E. M. de Melo e. Vôo da fênix crítica. Lisboa: Edições Cosmos, 1995.

CASTRO, E. M. de Melo e. Algorritimos: infopoemas. São Paulo: Musa, 1998. p. 7-19. 
DIDI-HUBERMAN, George. O que vemos, o que nos olha. Tradução de Paulo Neves. São Paulo: Ed. 34, 1998.

HATHERLY, A. Obra visual. Lisboa: Fundação Calouste Gulbenkian, 1990.

HATHERLY, A. A casa das musas - uma releitura crítica da tradição. Lisboa: Editorial Estampa, 1995.

HATHERLY, A. Um calculador de improbabilidades. Lisboa: Quimera, 2001.

KAC, Eduardo. "Key concepts of Holopoetry". Disponível em: <http://www.altx.com/ebr/ebr5/kac.htm>. Acesso em: 20 dez 2004.

MARQUES, Fabrício. Dez conversas - diálogos com poetas contemporâneos. Belo Horizonte: Gutenberg, 2004.

PIGNATARI, Décio. Nova poesia: concreta. In: Teoria da poesia concreta - textos críticos e manifestos 1950-1960. 2.ed. São Paulo: Livraria Duas Cidades, 1975.

PIMENTA, Alberto. O silêncio dos poetas. Lisboa: A regra do jogo, 1978. 2.ed. Lisboa: Cotovia, 2003.

PIMENTA, Alberto. Obra quase incompleta. Lisboa: Fenda, 1990.

PIMENTA, Alberto. IV DE OUROS. Lisboa: Fenda Edições, 1992.

RISÉRIO, Antônio. Ensaio sobre o poético em contexto digital. Salvador: F. Casa de Jorge Amado; COPENE, 1998. p. 45. 